\section{REFLEXÕES EM TORNO DO CONCEITO DE INCONSCIENTE SOCIAL}

\author{
Reflections on the Concept of Social Unconscious
}

Reflexiones en Torno al Concepto de Inconsciente Social

Réflexions sur le Concept de L'inconscient Social

\section{Resumo}

A fundação da psicanálise deu-se a partir da formulação do conceito de inconsciente, contudo é possível observar na teoria psicanalítica passagens em que à discussão sobre o tema ultrapassa o registro do universo individual para envolver as relações entre sujeito e cultura, herança filogenética e transmissão psíquica. Dentro dessa perspectiva, este trabalho tem o objetivo de introduzir a discussão sobre o conceito de inconsciente social rastreando seus antecedentes na psicanálise freudiana e na grupanálise inglesa. Tendo como metodologia a pesquisa teórica, o artigo apresenta investigações teóricas atuais lideradas pelos psicanalistas e grupanalistas Earl Hopper e Haim Weinberg. Suas investigações valorizam as interdependências entre indivíduo e sociedade, a coconstrução dos fatos sociais, como também as coerções e restrições de natureza inconsciente presentes nessas relações. O artigo utiliza-se de autores clássicos como Freud, Burrow, Fromm, Foulkes, Elias e Castoriadis e de conceitualizações dos contemporâneos Hopper, Weinberg, Dalal e Volkan. Na sequência aponta para investigações psicanalíticas e grupanalíticas sobre trauma e transmissão psíquica em grandes grupos traumatizados. O estudo sobre o inconsciente social ainda está em seu início, mas promete conferir novas dimensões às investigações sobre as relações entre psicanálise e cultura.

Palavras-chave: inconsciente; inconsciente social; psicanálise; grupanálise; trauma.

\section{Abstract}

The concept of unconscious is one of the cornerstones ofpsychoanalysis.However, in psychoanalytic theory it is possible to observe passages in whichthe discussion about this issue goes beyond the individual realm exploring relationships between subject and culture, phylogenetic inheritance and psychic transmission. Within this perspective, this paper aims to introduce the discussion on the concept of social unconscious pursuing its roots in Freudian Psychoanalysis and British Group Analysis. The methodology applied was a theoretical research.Under the leadership of the psychoanalysts and group-analysts Earl Hopper and Haim Weinberg, the article presents current research concerning its conceptualizations focusing on the interconnections between individual and society, the co-construction of social facts and the unconscious constraints and restraints in these relations. The article presents contributions of classical authors as Freud, Burrow, Fromm, Foulkes, Elias and Castoriadis as well as investigations of the contemporary scholars as Hopper, Weinberg, Dalal and Volkan. In the sequence, the paper points to psychoanalytic and group analytic research on trauma and psychic transmission in traumatized large groups. The study of the social unconscious is still in its beginning, but it will certainly add new dimensions to the investigation of the relationships between psychoanalysis and culture.
Artigo Original

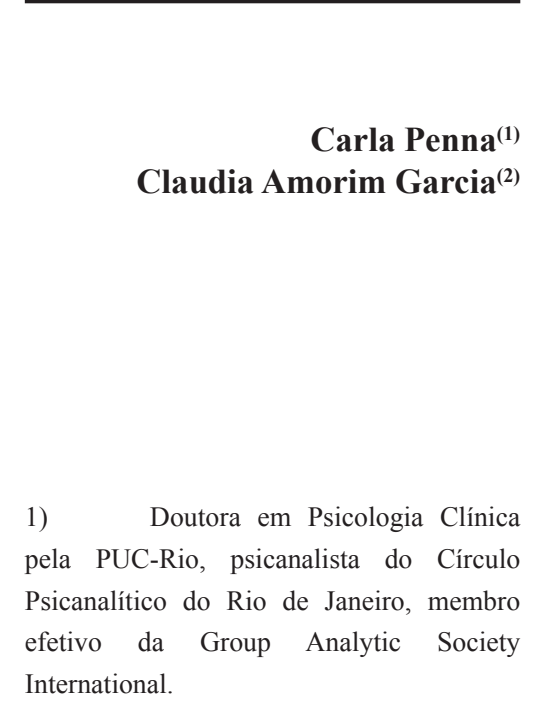

2) PhD, Wright Institute, California, USA. Professora associada da PUC-Rio, psicanalista do Círculo Psicanalítico do Rio de Janeiro.
Recebido em: 08/07/2013
Revisado em: $15 / 06 / 2015$
Aceito em: $22 / 06 / 2015$ 
Keywords: unconscious; social unconscious; psychoanalysis; group analysis; trauma.

\section{Resumen}

La fundación del psicoanálisis empezó con la formulación concepto de inconsciente. Sin embargo, es posible observar en la teoría psicoanalítica pasajes donde la discusión sobre el tema más allá del récord del universo individual, involucra las relaciones entre sujeto y la cultura, la herencia filogenética y la transmisión psíquica. En esa perspectiva, el presente trabajo tiene como objetivo introducir la discusión sobre el concepto de inconsciente social trazando sus antecedentes en el psicoanálisis freudiano y el grupo análisis Inglés. Con la metodología de la investigación teórica, el artículo presenta encuestas actuales teóricas realizadas por los psicoanalistas y grupo-analistas Earl Hoppery HaimWeinberg. Sus investigaciones valoran las interdependencias entre individuo y sociedad, la co-construcción de los hechos sociales, sino también las limitaciones y restricciones de naturaleza inconsciente de esas relaciones. El artículo recurre a autores clásicos como Freud, Burrow, Fromm, Foulkes, Elias y Castoriadis y conceptualizaciones de los contemporáneos Hopper, Weinberg, Dalal y Volkan.Despúes, examinainvestigaciones psicoanaliticas y grupo analíticas sobre el trauma y la transmisión psíquica en grandes grupos traumatizados. El estudio del inconsciente social está todavía en su infancia, pero se compromete a proporcionar una nueva dimensión a las investigaciones sobre la relación entre el psicoanálisis y la cultura.

Palabras clave: inconsciente; inconsciente social; psicoanálisis; grupo análisis; trauma.

\section{Résumé}

La fondation de la psychanalyse apparait au moment de la formulation $d u$ concept de l'inconscient, cependant est-il possible observer dans la théorie psychanalytique des "endroits» où la discussion sur le concept de l' inconscient dépasse l'enregistrement de l'univers individuel pour attendre les relations entre le sujet et la culture, l'héritage phylogénétique et la transmission psychique. Dans cette perspective ce travail a le but d'introduire une discussion sur le concept de l'inconscient social, cherchant leurs antécédents dans la psychanalyse freudienne et dans la psychanalyse anglaise des groups.En utilisant comme méthodologie la recherche théoriquecet article présente les enquêtes actuelles réalisé par lespsychanalystes et psychanalystes de groupe Earl Hopper et Haim Weinberg. Ses investigations apprécient les interdépendances entre individus et société, à la co-construction des faits sociaux et aussi aux contraintes et les restrictions de la nature inconscient de ces relations. .L'article présent les contributions des auteurs classiques comme Freud, Burrow, Fromm, Foulkes, Elias et Castoriadis et des concepts des contemporains Hopper, Weinberg, Dalal et Volkan. Ensuite, on fait une recherche psychanalytique et group analytique sur les traumatismes et la transmission psychique dans les grands groupes-traumatisés. L'étude sur l'inconscient social est encore à ses balbutiements, mais, ily a la promesse de nouvelles dimensions à la recherche sur les relations entre la psychanalyse et la culture.

Mots-clés: inconscient; inconscient sociaux; psychanalyse; psychanalyse du groupe; traumatisme.

É indiscutível o fato de que a fundação da psicanálise se deu a partir da formulação do conceito metapsicológico de inconsciente, no final do século XIX. Freud, no entanto, não foi o primeiro a empregar o termo. Antes dele, a noção de inconsciente já havia se tornado parte do imaginário de magnetizadores, filósofos, cientistas e literatos ao longo da história ocidental (Ellenberg, 1970). Assim, apesar do rastreamento da noção de inconsciente envolver uma pluralidade de influências marcantes, foi, sem dúvida, Freud que the conferiu um novo estatuto legitimando-a como conceito responsável por uma verdadeira revolução na forma de conceber a subjetividade humana.

É possível observar na teoria psicanalítica inúmeras passagens em que a discussão sobre o conceito de inconsciente ultrapassa o registro do universo individual para envolver as complexas relações entre sujeito e cultura, vida pulsional e civilização (Freud, 1921/1974b,1 923/1974c,1930/1976a,1933[1932]/1976b) bem como as interligações entre herança filogenética e a ontogênese e suas repercussões sobre o processo de transmissão psíquica (Freud, 1913/1974a, 1937/1976d,1939[1937]/1976e). Tais articulações, no entanto, permaneceram pouco exploradas na psicanálise freudiana, necessitando de um maior desenvolvimento teórico-conceitual. Tamanha tarefa exigiria estudo minucioso da obra freudiana que em diversas passagens - desde Totem e Tabu (Freud, 1913/1974a) até Moisés e o Monoteísmo (Freud, 1939[1937]/1976e) - o que nos remete à herança arcaica, ao "retorno do reprimido lento e não espontâneo, mas sob as influenciadas mudanças na condição de vida que preenchem a história da civilização humana" (Freud, 1939 [1937]/1976e, p. 157) fazendonos refletir sobre a possibilidade de existência de uma dimensão do inconsciente que transcende a experiência individual.O último parágrafo de Construções em Análise (Freud,1937/1976d) aponta nesta mesma direção:

Se considerarmos a humanidade como um todo e substituirmos o indivíduo humano isolado por ela, descobriremos que também ela desenvolveu delírios que são inacessíveis à crítica lógica e que contradizem a realidade. Se, apesar disso, esses delírios são capazes de exercer um poder extraordinário sobre os homens, a investigação nos conduz à mesma explicação no caso 
do indivíduo isolado. Eles devem seu poder ao elemento de verdade histórica que trouxemos à tona a partir da repressão do passado esquecido e primevo. (Freud, 1937/1976d, p. 304)

Referindo-se ao passado esquecido e primevo, e ao retorno do recalcado através da dimensão filogenética, Freud chamou atenção para as estreitas relações entre o inconsciente e a história da humanidade permitindo vislumbrar a possibilidade da existência de uma dimensão social do inconsciente. Parece ser neste sentido que declara, a propósito do superego:

A humanidade nunca vive inteiramente no presente. $\mathrm{O}$ passado, a tradição da raça e do povo, vive nas ideologias do superego e só lentamente cede às influências do presente, no sentido de mudanças novas; e, enquanto opera através do superego, desempenha um poderoso papel na vida do homem, independentemente das condições econômicas. A humanidade nunca vive inteiramente no presente. (Freud, 1933[1932]/1976b, p. 217)

Da mesma forma, o fragmento de 20 de julho em Achados, Ideias, Problemas (Freud, 1941[1938]/1976c) aguça a imaginação ao afirmar que "a hipótese de existirem vestígios herdados no id, altera, por assim dizer, nossos pontos de vista sobre ele" (Freud, 1941[1938]/1976c, p. 335), aludindo, talvez, às consequências teóricas que a postulação de uma herança arcaica poderia acarretar, questão que, no entanto, ficou em suspenso não tendo recebido um tratamento conceitual adequado.Nada, no entanto, parece mais eloquentemente exemplificar a posição freudiana sobre esta questão do que o parágrafo inicial de Psicologia de Grupo e Análise do Ego (Freud, 1921/1974a):

Apenas raramente e sob certas condições excepcionais, a psicologia individual se acha em posição de desprezar as relações desse indivíduo com os outros. Algo mais está envolvido na vida mental do indivíduo, como um modelo, um objeto, um auxiliar, um oponente, de maneira que, desde o começo, a psicologia individual, nesse sentido ampliado mais inteiramente justificável das palavras é, ao mesmo tempo, também psicologia social. (p. 91)

Ainda que este pressuposto epistemológico permeie a construção do arcabouço teórico freudiano, a psicanálise enquanto uma teoria do sujeito e prática clínica tem o indivíduo como seu foco central de atenção. Neste sentido, ainda que a "psicologia individual (seja) ao mesmo tempo psicologia social", o conceito psicanalítico de inconsciente diz respeito à compreensão do psiquismo individual. Foi apenas no final do século XX que a grupanálise inglesa, com a formulação do conceito de inconsciente social, retomou esta discussão dando seguimento à proposta freudiana deixada inacabada.

Este artigo visa apresentar, por meio de uma metodologia de pesquisa teórica, os antecedentes e as principais vicissitudes e tentativas de definição do conceito de inconsciente social. Na sequência, revela a importância do conceito de inconsciente social na análise da psicodinâmica de grandes grupos traumatizados. Trata-se uma investigação teórica em curso que se apoia em observações de intervenções psicossociais em países vítimas de traumas sociais severos. Observações sobre o inconsciente social nesses contextos apontam para um vasto campo de pesquisa em psicanálise e grupanálise que vem sendo mapeado.

\section{Antecedentes}

Pesquisas recentes revelam que o psicanalista Trigant Burrow - proscrito pela comunidade psicanalítica na década de 20 por tentar considerar as influências do contexto social na psicanálise desde o início da constituição subjetiva - já se referia à ideia de inconsciente social no artigo "Social Images and Reality" de 1924 (Pertegato; Pertegato, 2013). Depois dele, segundo Hopper (2003, p.159), Karen Horney, em 1937, utilizou a noção de inconsciente social no trabalho clínico. Foi, no entanto, Erich Fromm, a partir da década de 1960, especificamente em 1962 e, mais tarde, em 1976, no volume 3 de seus escritos póstumos publicados em $A$ descoberta do inconsciente social (Fromm, 1992), o primeiro autor a empregar o termo inconsciente social para se referir às formas inconscientes de internalização do mundo social e às características do mundo social externo de que não se tem consciência (Hopper; Weinberg, 2011). Sua definição de inconsciente social aproximava-se do que denominou de "mente inconsciente da sociedade" (Fromm, 1992, p. 79) e articulava-se com a noção de filtro social de origem claramente freudiana:

Antes de mais nada, vejamos o conceito de filtro social que determina quais experiências são permitidas de chegar à consciência. Esse filtro, que consiste numa língua, numa lógica e costumes (ideias e impulsos tabus ou permitidos, respectivamente) é de natureza social. É específico em cada cultura e determina o inconsciente social (...). O recalcamento de certos impulsos e ideias tem uma função muito real e importante para o funcionamento da sociedade e, em consequência, todo o aparato cultural serve ao propósito de conservar intacto o inconsciente social. (Fromm, 1992, p. 80)

Essa definição sugere que existem uma língua, uma lógica e costumes específicos de cada cultura que consistem no filtro social responsável pelo recalque de impulsos e ideias que, por sua vez, compõem o inconsciente social. 
Essas ideias de Fromm, entretanto, não tiveram maior desenvolvimento e foi só então com a grupanálise que o conceito de inconsciente social começou a adquirir uma consistência teórica, estando ainda, nos dias atuais, em pleno processo de elaboração.

A grupanálise investiga as formações grupais e a clínica de referencial psicanalítico com grupos dentro de um paradigma que se situa na interface da psicanálise e da sociologia. Sua origem remonta aos trabalhos com grupos na psiquiatria e na psicanálise no pós-guerra da Inglaterra, tendo como principais articuladores, o psicanalista alemão, naturalizado inglês, S.H. Foulkes e o sociólogo Norbert Elias. Dentre as diferentes correntes de orientação psicanalítica no estudo de grupos, a grupanálise confere uma especial atenção à dimensão social das relações humanas. No trabalho com grupos analíticos Foulkes buscou desenvolver não apenas um novo método psicoterápico, mas "construir uma nova teoria na qual o indivíduo não poderia ser apreciado em separado do contexto social, já que este o definiria" (Brown; Zinkin, 2000, p. 1). A ênfase que Foulkes atribuiu ao social foi o resultado de sua colaboração íntima com Norbert Elias - que se opunha à dicotomia indivíduo e sociedade presente no pensamento ocidental (Elias, 2010, 1987) - aliada às contribuições teóricas da psicanálise e da neurobiologia de orientação holística de Kurt Goldstein. Sua concepção intersubjetiva, tributária da antropologia de Malinovsky, da sociologia de Karl Mannheim, da historiografia de Franz Borkenaue das contribuições dos debates freudo-marxistas foram fundamentais para a construção de seu pensamento que caminhava contra a tendência da psicanálise da época totalmente mergulhada no universo intrapsíquico kleiniano (Nitzgen, 2011). Tal confluência de diferentes disciplinas resultou no desenvolvimento de uma técnica grupo terápica fundamentada no pressuposto de que indivíduo e sociedade representam diferentes níveis de manifestação de um mesmo fenômeno em um todo integrado (Elias, 2010). A formulação do conceito de matriz definida como uma "rede, uma matriz de relacionamentos que ocorrem em um dado grupo; um solo comum compartilhado que determina o sentido e o significado de todas as comunicações e interpretações, verbais ou não verbais" (Foulkes, 2012a, p. 292) revelou como Foulkes integrou essas influências.

Após a Segunda Guerra Mundial, a psiquiatria social, a produção teórico-clínica do Tavistock Institute of Human Relations e a grupanálise inglesa, impulsionados pelos experimentos com grupos e comunidades terapêuticas realizados durante a guerra no Hospital Northfield, tiveram grande desenvolvimento em solo inglês. A partir da década de 1970 os primeiros trabalhos com grandes grupos passaram a ser realizados, inicialmente como "experiências de laboratório", em conferências da Universidade de Leicester ou na Sociedade de Grupanálise (Penna, 2009). Nesses contextos, foi possível detectar a intensidade da emergência de processos inconscientes, especialmente em contextos marcados pelo trauma, que apontavam para a ideia do inconsciente social (Hopper, 2003).

Embora tenha, em diversas passagens de sua obra, se referido ao inconsciente social, Foulkes nunca elaborou sua conceitualização de forma mais sistemática, nem o utilizou em seu trabalho clínico. Na verdade, apenas afirmava que existiam diversos fatores e forças biológicas, sociais e culturais, de que as pessoas não se davam conta, envolvidos nas relações sem se aprofundar na discussão. Sua primeira referência explícita à ideia do inconsciente social pode ser encontrada no artigo "Group Therapy" (Foulkes, 2012a):

A situação grupanalítica, ao mesmo tempo em que lida com o inconsciente no sentido freudiano, traz em operação e perspectiva uma área totalmente diferente da qual o indivíduo não tem igualmente consciência. Além disso, o indivíduo tão modelado e compelido por essas colossais forças como por seu próprio id defende-se totalmente contra seu reconhecimento sem estar consciente, mas de formas e modos bem diferentes. Pode-se assim falar de um inconsciente interpessoal ou social. (p. 52)

Nesta primeira menção ao conceito, Foulkes parte do inconsciente freudiano individual para refletir sobre a existência de um inconsciente social. Devido à sua formação como psicanalista, esta primeira definição do conceito encontrava-se muito próxima da concepção freudiana de inconsciente, o que também pode ser evidenciado na sua afirmativa de que a "tradução do inconsciente social deveria seguir os mesmos princípios de tradução do inconsciente recalcado freudiano" (Foulkes, 2012a, p. 55). Para Weinberg (2007), no entanto, Foulkes, deu um passo à frente na definição freudiana de inconsciente, incluindo em sua formulação a ideia de que forças sociais afetavam processos interpessoais e transpessoais.

Lavie (2011) recuperou um discurso de Foulkes, proferido em 1965 na Hebrew University, que demonstrava sua visão sobre as interdependências entre indivíduosociedade (Elias, 2010) demonstrando como uma combinação de sentimentos, angústias, falsas crenças e concepções errôneas constituem o modus operandi do inconsciente social (Lavie, 2011, p.172). Nessa passagem, é possível perceber como Foulkes vislumbrava o inconsciente social, entretanto sua preocupação na época parecia estar mais focada no caráter inconsciente das falsas dicotomias modernas entre indivíduo e sociedade e sua transmissão do que no inconsciente social em si.

A última referência sobre o conceito em Foulkes aparece em "Problems of Large Groups" (Foulkes, 1975). Neste artigo, discutiu a importância da ideia de inconsciente social enquanto fenômeno multipessoal afirmando que a herança de um indivíduo não inclui apenas os fatores genéticos ou biológicos herdados já que a herança cultural, transmitida de geração a geração, ocupa 
um papel preponderante nesse processo. Assim as ideias de Foulkes sobre o entrelaçamento entre indivíduo e cultura, além de apontarem para a importância dessas interrelações, aproximam-se das pesquisas de Horkheimer, Adorno e Frommda década de 30 , especialmente em relação às investigações sobre os "fundamentos sócio-psicológicos do caráter autoritário" (Nitzgen, 2011, p. 17).

Dessa forma, desde as décadas de 1960 e 1970, reflexões em torno da possível existência de um inconsciente social começaram a ser intuídas e esboçadas por Foulkes (1975, 2012b) e seus seguidores. Dentre eles merece destaque o trabalho desenvolvido pelo sociólogo e psicanalista Earl Hopper (2003; Hopper; Weinberg, 2011) que, partindo de inter-relações entre sociologia, psicanálise e grupanálise, deu início na década de 90 a uma investigação que visava compreender como diferentes características de grupos e sistemas sociais eram internalizados pelas pessoas, observação que acabou levando-o às investigações sobre o inconsciente social. Sua experiência clínica com pacientes difíceis, com sobreviventes do Holocausto e com o estudo sobre a transmissão psíquica transgeracional, aliada ao trabalho em settings de grandes grupos traumatizados foram fundamentais para o desenvolvimento de suas ideias (Hopper, 2003).

Nos últimos anos, Hopper associou-se à Haim Weinberg, organizando um grupo de trabalho que reúne grupanalistas e psicanalistas em torno do esforço de definir o inconsciente social. Essa empreitada resultou na publicação, em 2011, do primeiro volume de uma trilogia The Social Unconscious in Persons, Groups and Societies - Mainly Theory (Hopper \& Weinberg, 2011) e de um segundo volume, The Social Unconscious in Persons, Groups and Societies - Mainly Foundation Matrices (Hopper \& Weinberg, 2015). Embora ainda existam divergências quanto à formulação do inconsciente social é possível defini-lo como:

(...) a existência de restrições e de arranjos sociais, culturais e comunicacionais, dos quais as pessoas não estão conscientes - unaware - em diferentes graus, incluindo angústias, fantasias, mitos, defesas e relações objetais assim como vários aspectos de fatores e forças sociais, culturais, econômicas e políticas, muitos dos quais também foram coconstruídos, inconscientemente, por membros de grupos específicos. (Hopper \& Weinberg, 2011, p. xxvi)

Para Hopper, o vocábulo arranjo é um eufemismo para sistemas, estruturas e suas diferentes manifestações, tais como, no caso de sociedades, suas instituições e organizações específicas (Hopper; Weinberg, 2011, p. xxx). Da mesma forma, estar fora da consciência - unaware é também, para Hopper, um eufemismo para processos inconscientes de uma maneira geral. Nesse sentido, o inconsciente social envolve o não-consciente, o inconsciente dinâmico, o recalcado, o clivado - split off - e o préconsciente (Hopper \& Weinberg, 2011, p. xxx). Portanto, arranjos sociais, culturais e comunicacionais podem estar fora da consciência e representar processos inter-relacionais que envolvem um grande número de pessoas e o que ocorre entre elas, constituindo, assim, o inconsciente social que, por sua vez, é mantido através de uma série de defesas contra a emergência de angústias em relação a fenômenos sociais.

\section{O inconsciente social: $\mathbf{E m}$ busca de uma definição}

Definir o que é o inconsciente social não é tarefa das mais fáceis, já que, em tese o conceito discute a ideia de inconsciente compartilhado presente em membros de culturas e sociedades específicas. Mesmo após alguns anos de debate, formulações teóricas consistentes e contribuições de psicanalistas e de grupanalistas de vários países e de profissionais de orientações afins como a sociologia, a filosofia, a psicologia analítica, a teoria sistêmica não existe ainda uma unidade em torno do conceito.

Grande parte das dificuldades em relação à compreensão do conceito de inconsciente social reside no fato de que muitas pessoas se perguntam como uma sociedade poderia apresentar um inconsciente. De fato, não é possível atribuir aspectos inconscientes a uma sociedade como tal, embora isso possa ser feito em relação a seus membros (Hopper; Weinberg, 2011) que podem compartilhar de aspectos inconscientes derivados de um mesmo processo social ou de uma história social. Isto é, o inconsciente social relaciona-se à internalização de fatos sociais, normas e aspectos culturais que não estão conscientes, incluindo as representações das relações de poder presentes na psique (Dalal, 1998, 2011) diferentemente do que ocorre na constituição do inconsciente individual que se constitui a partir de uma trajetória individual singular. Considerandose, no entanto, as inter-relações entre indivíduo e sociedade (Dalal, 1998; Elias, 1987) fica, de fato, praticamente impossível separar o inconsciente social do inconsciente individual. Nesse sentido, a observação apresentada por Knauss da Universidade de Heildelberg segundo a qual "não existe um inconsciente grupal, nem tampouco um inconsciente social, ou um inconsciente cultural ou coletivo, pois todo inconsciente é grupal" (Knauss, 2005, p. 55) torna-se pertinente, colocando em questão o conceito.

Em 2007, Weinberg procurou sistematizar o conceito de inconsciente social diferenciando-o de noções como inconsciente coletivo e superego. Tomando por base a leitura grupanalítica, afirmou que, quando duas ou mais pessoas se reúnem, existe um campo inconsciente compartilhado, ao qual o sujeito pertence, embora não esteja consciente de sua existência. Dessa maneira, torna-se possível falar de um inconsciente relacional que, para ele, é um processo 
cocriado pelas pessoas, mas que remete a algo além das contribuições individuais de cada um deles. Assim, se num grupo pequeno é possível observar que dois ou mais membros podem compartilhar fantasias inconscientes e mecanismos de defesa comuns, é possível transportar essa mesma possibilidade para comunidades e até mesmo para sociedades. Desse modo, se é possível constatar a presença de um inconsciente nos pequenos grupos, pode-se também inferir a existência de um inconsciente em grupos maiores - o inconsciente social (Weinberg, 2007, p. 309).

De forma similar ao inconsciente individual, o inconsciente social compartilha com o inconsciente freudiano das mesmas características no que concerne à temporalidade e à espacialidade. Assim, também se caracteriza pela atemporalidade, permitindo que os membros de um grupo possam reavivar e alimentar no presente relações e emoções vivenciadas em um passado remoto como acontece em determinadas situações de grande grupo quando colapsos temporais - time collapse (Volkan, 2004, p.51; 2013) - atualizam emoções recalcadas. Em situações regressivas de grande grupo ou diante de traumas massivos, fantasias e angústias inconscientes podem ser reativadas e afetar o comportamento das sociedades em larga escala porque, filogeneticamente o inconsciente social precede o inconsciente individual, permitindo que um inconsciente compartilhado possa ser construído entre desconhecidos (Weinberg, 2007).

Embora o inconsciente social possa, em um primeiro momento, ser confundido com o inconsciente coletivo junguiano, eles guardam diferenças significativas entre si (Weinberg, 2007). Jung (1996) distinguiu o inconsciente individual do inconsciente coletivo ao afirmar que o inconsciente coletivo continha imagens arquetípicas, definidas como predisposições psíquicas de caráter universal que se manifestavam, portanto, em todas as pessoas e culturas. Os arquétipos, contudo, não estavam associados a memórias passadas e seriam formas sem conteúdo que pertenciam à herança filogenética de todas as sociedades (Hopper \& Weinberg, 2011). O inconsciente social por sua vez, é comum a pessoas de uma cultura específica e está baseado em memórias compartilhadas por seus membros, especialmente as traumáticas que podem ser transmitidas por gerações e que permanecem recalcadas no inconsciente daquele determinado grupo (Volkan, 2002). Além disso, o inconsciente social não apresenta uma perspectiva mítica ou cósmica como se observa no inconsciente coletivo (Hopper; Weinberg, 2011, p. xlix). Apesar dessas diferenças importantes, o conceito de inconsciente social pode ser aproximado de elaborações teóricas junguianas mais contemporâneas como as noções de inconsciente interpessoal ou inconsciente compartilhado (Farris, 2011) que formam a base para a compreensão da realidade como coconstruída através das relações interpessoais e do processo de socialização.
$\mathrm{Na}$ filosofia, o conceito de imaginário social, apresentado em 1975 por Castoriadis (1982) que partiu de uma crítica ao marxismo para introduzir uma nova visão teórica da sociedade, vista como instituição imaginária, guarda também significativas semelhanças com o conceito de inconsciente social da grupanálise. De fato, embora revele um viés mais filosófico, baseado em uma crítica à teoria marxista, Castoriadis postulou uma teoria que penetrou nas entranhas das formações histórico-político-sociais. É possível identificar em Castoriadis (1982) passagens extremamente próximas do conceito de inconsciente social da grupanálise tais como:

(...) para que uma significação imaginária exista, são necessários significantes coletivamente disponíveis, mas, sobretudo, significados que não existem sob a forma sob o qual existem os significados individuais - como percebidos, pensados ou imaginados por tal sujeito. (Castoriadis, 1982, p. 175)

Ou mesmo ainda, por meio da própria definição de imaginário social:

Este elemento, que dá à funcionalidade de cada sistema institucional, sua orientação específica, que sobredetermina a escolha e as conexões das redes simbólicas, criação de cada época histórica, sua singular maneira de viver, de ver e fazer sua própria existência, seu mundo e suas relações com ele, esse estruturante originário, esses significado-significante central, fonte do que se dá cada vez como sentido indiscutível e indiscutido, suporte das articulações e das distinções do que importa e do que não importa, origem do aumento da existência dos objetos de investimento prático, afetivo e intelectual, individuais ou coletivos - este elemento nada mais é do que o imaginário da sociedade ou da época considerada. (Castoriadis, 1982, p. 175)

Embora sejam evidentes as semelhanças entre os dois conceitos, os arcabouços teóricos utilizados por Castoriadis e Foulkes são distintos e, se Castoriadis tendia mais para a filosofia e a ciência política, articulando-as com a psicanálise francesa, Foulkes preocupava-se com as bases epistemológicas da grupanálise, com as relações indivíduo-sociedade e com a clínica com grupos. Para Nitzgen (2011), na orientação epistemológica de Foulkes, a noção de inconsciente social remetia a uma abstração que adquiriu sentido a partir das ideias de Castoriadis e mais especificamente através do que este denominou de "magma dos processos sócio-históricos" (Nitzgen, 2011, p. 18).

$\mathrm{Na}$ verdade, a ideia de um inconsciente social implica no fato de que existe uma herança cultural, mitos e motivos desconhecidos e recalcados que pertencem a uma dada sociedade e que acabam interferindo nas ações de 
seus membros (Hopper; Weinberg, 2011). Contudo, essa herança difere daquela atribuída ao superego herdado dos pais, tal como Freud (1923/1974b) postulou, embora seja importante asseverar que a internalização das regras seja absorvida pelo infante. Neste sentido, o superego é uma instância psíquica individual o que justifica o aspecto único e singular da internalização das normas sociais por cada sujeito. Isto é, a apropriação e interpretação das restrições sociais variam de pessoa para pessoa. $\mathrm{O}$ inconsciente social, por sua vez, é comum a pessoas que pertencem a uma mesma sociedade e representa, portanto, uma forma mais homogênea de internalização das normas culturais de uma dada sociedade. De uma maneira geral, portanto, o superego, embora apresente valores herdados restringese, à psicodinâmica individual inconsciente, ou de um número restrito de pessoas, enquanto que o inconsciente social abrange um dado sistema social desde suas origens (Hopper; Weinberg, 2011).

Dentro dessa perspectiva, o conceito de matriz postulado por Foulkes $(1975,2012 b)$ torna-se fundamental para o debate sobre o inconsciente social. Sabe-se que membros de um mesmo grupo compartilham não só de uma mesma matriz - termo que significa mater, mãe - isto é, de uma mesma rede de relacionamentos, mas também das conexões inconscientes estabelecidas no interior daquele grupo (Hopper\& Weinberg, 2011). A noção de matriz carrega consigo uma multidimensionalidade de sentidos, podendo ainda ser vista como uma rede sóciocultural-comunicacional. Assim, os membros de um grupo, comunidade ou nação têm em comum uma matriz fundadora produzida no seio de cada grande grupo ou sistema social. Isso significa que "mesmo um grupo de estranhos, pertencentes (...) à mesma cultura, partilham de uma matriz psíquica fundadora (foundationmatrix)" (Foulkes, 2012a, p. 228). O conceito de matriz tornou possível não só a exploração de aspectos inconscientes de um determinado grupo, mas também "a observação de fatos que não são nem da ordem da objetividade, nem da ordem da subjetividade, mas que são coconstruídos e intersubjetivos, ou em efeito, transicionais" (Hopper \& Weinberg, 2011, p.xlvi).

Isto é, para os sujeitos interpessoais estudados por Foulkes, o mundo social não estava relacionado nem a um dentro ou a um fora ou mesmo a um mundo interno e um mundo externo e social, "mas sim a áreas de transicionalidade e a objetos transicionais, descobertos ou inventados, ou precisamente coinventados" (Hopper; Weinberg, 2011 p.xxx). É neste sentido que Scholz (2014) afirma que a leitura de Foulkes sobre as relações indivíduosociedade introduziu um novo paradigma na investigação das formações grupais, pois suas descrições envolviam sempre o que estava "entre" - in between - os membros de um grupo, permitindo vislumbrar a existência de um inconsciente interativo e comunicacional. Neste aspecto, as influências de Elias (2010) são claras, revelando um Foulkes afinado com o pensamento inter-relacional trabalhando desde a década de 50 com conceitos bastante semelhantes àqueles desenvolvidos por Winnicott (1971) no estudo da transicionalidade.

$\mathrm{O}$ estudo sobre o inconsciente social encontra-se relacionado às investigações sobre o que foi denominado, no século XX, de processos que envolvem a internalização do mundo social - e que foram caros aos freudo-marxistas e aos frankfurtianos - propiciando, no entanto, uma nova dimensão para o debate. Hopper (2003; Hopper \& Weinberg, 2011) afirma que o inconsciente social sempre se refere às restrições - constraints - que implicam na forma como os objetos sociais foram internalizados e às repressões - restraints - que esses mesmos objetos sofreram. Dentro desta visão chama atenção para o fato de que o conceito de restrição - constraint- provém do trabalho de Durkheim e de outros precursores da sociologia francesa que utilizaram o termo para discorrer sobre as restrições - constraints existentes em relação a fatos sociais (Hopper \& Weinberg, 2011). Nesse sentido, recorda que, embora esses autores nunca tenham se referido à ideia do inconsciente social, eles postulavam a existência de uma consciência coletiva, fundada em fatores sociais que eram internalizados e compartilhados em uma dada sociedade, no entanto essa ideia não implicava presença de um inconsciente na sociedade (Hopper \& Weinberg, 2011, p. xxxv). Embora Hopper empregue uma terminologia, às vezes mais afeita à tradição sociológica - que envolve diferenciações entre os conceitos de constraintserestraints, bem como os termos sistema social, fato social ou objeto social, pouco empregados no vocabulário psicanalítico - sua discussão é importante no que se refere à reflexão sobre a forma como os objetos sociais são internalizados dentro de uma visão grupanalítica e psicanalítica (Hopper; Weinberg, 2011).

Ainda na Inglaterra a discussão sobre o inconsciente social, e especialmente sobre a constituição dos processos subjetivos a partir da metabolização de objetos sociais, encontrou em Dalal $(1998,2011)$ um pensador original. Dalal (1998) afirmou que não foi prerrogativa de Foulkes ter apontado para o inconsciente social, já que a formulação do social a priori é uma temática comum a um grande número de escolas. No entanto, a questão de "como em determinados locais os seres humanos são levados a partilhar uma visão comum de um estado de coisas ou a tomar como certos determinados preceitos?" (Dalal, 2011, p. 254) permanece. Segundo Dalal (1998), variadas escolas de pensamento afirmam que a resposta está nas convenções sociais nas quais os indivíduos estão inseridos desde o nascimento, o que justifica a intuição do inconsciente social em várias delas. Embora tenha conferido importância às ideias de Foulkes sobre o inconsciente social, a visão de Dalal $(1998,2011)$ amplia ainda mais o escopo de análise do conceito, colocando-o ainda em sintonia com contribuições psicanalíticas contemporâneas aliadas ao pensamento de 
Elias (2010) e Foucault (2012), ao afirmar que:

O inconsciente social não é o social no inconsciente, ou seja, não se trata apenas da forma como alguém é afetado pelo seu sistema cultural particular. O inconsciente social inclui, mas é maior do que o que pode ser chamado de inconsciente cultural. O inconsciente cultural pode ser descrito como consistindo de normas, hábitos e formas de pensar de uma cultura particular (...) O inconsciente social inclui as relações de poder estabelecidas entre os discursos. (Dalal, 1998, p. 212)

Dessa forma, para Dalal $(1998,2011)$ as relações de poder são partes constitutivas do inconsciente social que se encontra permeado por ideologias e discursos que acabam legitimando um senso comum absorvido no social na medida em que as formações discursivas veiculam “categorias de linguagem e ideias, mas também práticas que impõem taxonomias - sistemas de inclusão e exclusão - sobre o mundo e sobre o psíquico" (Dalal, 2011, p. 258).

Ao incluir as relações de poder na investigação sobre o inconsciente social, Dalal complexifica o debate em torno da definição de um conceito que já parecia bastante ampla. As pesquisas demandam, portanto, um esforço interdisciplinar em torno da investigação de uma miríade de processos inconscientes que se interconectam tais como a natureza social das relações humanas e suas implicações sobre a constituição da subjetividade. Merece também destaque a reflexão sobre a questão de que fatos sociais são coconstruídos sendo influenciados por coerções e restrições presentes nos diferentes tipos de grupos, desde os familiares ou comunitários passando por outros tipos de agrupamentos (groupings) tais como classe social ou grupo étnico (Hopper; Weinberg, 2011).

\section{O inconsciente social e os grandes grupos traumatizados contemporâneos}

Areflexão sobre o inconsciente social tem se apresentado como particularmente relevante na compreensão dos grandes grupos contemporâneos, especialmente nos grupos traumatizados. De fato, é por meio da psicodinâmica de grandes grupos que desejos, mitos, fantasias, restrições e recalcamentos, enquanto elementos componentes do inconsciente social apresentam-se de forma pregnante. Dentro dessa perspectiva, Weinberg (2007; Hopper; Weinberg, 2011) confere um acento especial à questão do trauma e sua relação com o inconsciente social apresentado como:

(..) um inconsciente coconstruído e partilhado por membros de um sistema social como uma comunidade, uma sociedade, nação ou cultura. Ele inclui angústias, fantasias, defesas, mitos e memórias compartilhados. Seus tijolos são compostos por "traumas selecionados" e "glórias selecionadas". (Weinberg, 2007, p. 312)

A definição de Weinberg inclui os conceitos de traumas selecionados e glórias selecionadas postulados por Volkan $(2002,2004,2013)$ estabelecendo assim uma conexão direta entre os estudos sobre grandes grupos étnico-nacionais, as sociedades traumatizadas e o conceito de inconsciente social. Em sociedades traumatizadas, isto é, em grandes grupos regredidos, mecanismos de defesa como clivagem, projeção, idealização, recalcamento e recusa encontram-se presentes, determinando e influenciando os comportamentos individuais e coletivos (Hopper; Weinberg, 2011, 2015). É justamente através do uso dessas defesas que o inconsciente social se manifesta bem como através de pressupostos ou asserções presentes no senso comum e que são invariavelmente expressões do inconsciente social. Além disto, reflexões psicanalíticas contemporâneas apontam para as relações entre o inconsciente social, as formas do negativo (Green, 1993) e a transmissão psíquica (Faimberg, 2005) descortinando novos caminhos, tanto para a análise de pacientes difíceis quanto para a compreensão dos efeitos de transmissões psíquicas na família e no social (Volkan, 2013).

Como Hopper e Weinberg (2011) argumentam uma sociedade traumatizada faz uso de mecanismos inconscientes específicos - principalmente mecanismos de defesa - coconstruídos e compartilhados por seus membros que podem levar pessoas, grupos ou até mesmo uma sociedade inteira a agir, em determinadas circunstâncias, sob influência do inconsciente social. Traumas envolvendo dolorosos eventos resultam na dificuldade de lidar com o reconhecimento da realidade ou originam defesas que visam evitar o contato com memórias traumáticas ou dolorosas. Evitar a recordação dessas lembranças, o que envolve o emprego de mecanismos de defesa é, portanto, a essência do inconsciente social o que justifica o fato de que a transmissão psíquica de conteúdos recalcados pode perpassar gerações por séculos. Esse tipo de reflexão está em sintonia com pesquisas sobre as sociedades regredidas e traumatizadas estudadas por Volkan, nas quais a transmissão psíquica transgeracional (Volkan, 2002, 2013), a telescopagem de gerações (Faimberg, 2005) e os traumas e as glórias selecionados (Volkan, 2002, 2004, 2013) revelam o inconsciente social dos membros do grupo afetado. Através de traumas selecionados ou glórias selecionadas, uma espécie de trauma ecoante parece persistir e transmitirse psiquicamente pelo negativo (Garcia; Penna,2010) no inconsciente social das culturas afetadas. Em países como Israel, Palestina, Alemanha, Sérvia, Croácia, República Checa, Hungria ou no Leste Europeu essas manifestações psíquicas são evidentes. Neste sentido a análise e a elaboração de conteúdos presentes no inconsciente social 
são de fundamental importância para a compreensão da psicopatologia de muitos fenômenos sociais como também para o desenvolvimento de estratégias de intervenção visando a elaboração de conteúdos e experiências traumáticas. O principal objetivo do trabalho com o inconsciente social é, portanto, revelar as lembranças traumáticas coletivas e o impacto dessas memórias inconscientes na sociedade e em seus membros(Penna,2014).

Sem dúvida alguma, as sociedades traumatizadas são um campo fértil para o estudo e a compreensão do inconsciente social. As pesquisas sobre essas relações ainda estão em seu início e psicanalistas, especialmente aqueles que viveram sob regimes totalitários na Europa, começam a se dedicar à exploração das inter-relações entre a psique individual e as estruturas e funções dos sistemas sociais, ou seja, dedicam-se a investigar a produção de subjetividade em regimes totalitários e seus efeitos sobre a psicologia e a psicopatologia individual especialmente após o colapso invariavelmente traumático desses regimes (Hopper; Weinberg, 2011, 2015; Klímová, 2011; Mojovic,2011).

\section{Considerações finais}

$\mathrm{O}$ artigo procurou apresentar os principais argumentos teóricos na psicanálise freudiana e na grupanálise inglesa que contribuíram para a formulação do conceito de inconsciente social. Desde os primórdios da psicanálise as relações entre sujeito e cultura fizeram parte das preocupações de Freud, mas por muitos anos essas inter-relações não foram privilegiadas dentro do arcabouço teórico da psicanálise. Contudo, o desenvolvimento do paradigma intersubjetivo da psicanálise aliado às contribuições da grupanálise e das ciências sociais, bem como a observação de grandes grupos traumatizados, permitiu que a partir do final da década de 90, investigações sobre como os diferentes sistemas sociais são inconscientemente internalizados pelos sujeitos fossem revelados. Tais investigações conduziram à observação do conceito de inconsciente social e suas principais definições ainda em estudo. As observações sobre as inter-relações entre o inconsciente social, as relações de poder e o trauma coletivo prometem constituir-se como um vasto campo de pesquisa para a psicanálise e para a grupanálise no século XXI.

\section{Referências}

Brown, D., \&Zinkin, L. (2000). The psyche and the social world.Developments in GroupAnalytic Theory London: Jessica Kingsley.

Castoriadis, C. (1982).A instituição imaginária da sociedade. São Paulo: Paz e Terra.
Dalal, F. (1998).Taking the group seriously: Towards a post-Foulkesian group analytic theory. London: Jessica Kingsley.

Dalal, F. (2011).The social unconscious and ideology: In clinical theory and practice. InE. Hopper, \&H.Weinberg(Eds.),The social unconscious in persons, groups and societies. Mainlytheory(Vol. 1, pp.243-263).London: Karnac.

Elias, N.(1987).A sociedade dos individuos. Rio de Janeiro: Zahar.

Elias, N.(2010). Introdução à sociologia. Lisboa: Edições 70.

Ellenberg,H.(1970).The discovery of the unconscious. New York: Basic Books.

Faimberg,H.(2005).The telescoping of generations: Listening to the narcissistic links between generations. London: Routledge.

Farris,S. (2011).The social unconscious and the collective unconscious: The Jungian perspective. InE. Hopper,\& H. Weinberg (Eds.), The social unconscious in persons, groups and societies. Mainly theory(Vol.1, pp. 295319). London:Karnac.

Foulkes, S. H.(1975). Problems of the large groups. In L. Kreeger (Org.), The large group: Dynamics and therapy(pp. 33-56). London:Karnac.

Foulkes, S. H. (2012a).Group therapy. InS.H. Foulkes, Therapeutic group analysis. London:Karnac.

Foulkes, S. H. (2012b). Therapeutic group analysis. London:Karnac.

Freud, S. (1974a). Totem e tabu. In J. Strachey (Ed.),Edição Standard Brasileira das Obras Completas de Sigmund Freud (Vol.13). Rio de Janeiro: Imago. (Originalmente publicado em 1913[1912-1913])

Freud, S. (1974b).Psicologia de grupo e análise do ego.In J.Strachey (Ed.),Edição Standard Brasileira das Obras Completas de Sigmund Freud (Vol.18). Rio de Janeiro: Imago. (Originalmente publicado em 1921)

Freud, S.(1974c).O ego e o id. In J. Strachey (Ed.),Edição Standard Brasileira das Obras Completas de Sigmund Freud(Vol.19). Rio de Janeiro: Imago.(Originalmente publicado em 1923) 
Freud, S.(1976a). O mal-estar na civilização. In J. Strachey (Ed.),Edição Standard Brasileira das Obras Completas de Sigmund Freud(Vol.21). Rio de Janeiro: Imago. (Originalmente publicado1930[1929])

Freud, S.(1976b). A dissecção da personalidade psíquica. In J. Strachey (Ed.), Edição Standard Brasileira das Obras Completas de Sigmund Freud (Vol.22). Rio de Janeiro:Imago.(Originalmente publicado em1933[1932])

Freud, S. (1976c). Breves escritos. Achados, ideias, problemas. In J. Strachey (Ed.), Edição Standard Brasileira das Obras Completas de Sigmund Freud (Vol.23). Rio de Janeiro: Imago. (Originalmente publicado em 1941[1938])

Freud, S. (1976d). Construções em análise. In J. Strachey (Ed.), Edição Standard Brasileira das Obras Completas de Sigmund Freud (Vol.23).Rio de Janeiro: Imago. (Originalmente publicado em 1937)

Freud, S. (1976e). Moisés eo monoteísmo. In J. Strachey (Ed.), Edição Standard Brasileira das Obras Completas de Sigmund Freud (Vol.23). Rio de Janeiro: Imago. (Originalmente publicado em 1939[1934-1938])

Foucault, M. (2012).Microfisica do poder(28 ${ }^{\mathrm{a}}$ ed.). Rio de Janeiro: Graal.

Fromm, E.(1992).A descoberta do inconsciente social. São Paulo: Manole.

Garcia, C.,\& Penna, C. (2010). O trabalho do negativo e a transmissão psíquica. Arquivos Brasileiros de Psicologia63(2),68-79.

Green,A.(1993).El trabajo de lo negativo.Buenos Aires: Ed Amorrortu.

Hopper,E.(2003).Social unconscious: Selected papers. London: Jessica Kingsley.

Hopper, E.,\&Weinberg, H.(2011). Introduction. InE. Hopper,\& H.Weinberg (Eds.),The social unconscious in persons, groups and societies.Mainly theory(Vol. 1, pp.xxiii-lv). London:Karnac.

Hopper, E.,\& Weinberg, H. (2015).The social unconscious in persons, groups and societies.Mainly Foundation Matrices(Vol.2).London:Karnac.

Jung, C.G. (1996). The archetypes and the collective unconscious. In C. G. Jung,Collected Works of C. G.
Jung. Princeton: Princeton University Press.

Klímová, H. (2011).The false we/the false collective self. In E. Hopper,\& Weinberg, H. (Eds.),The social unconscious in persons, groups and societies.Maily Theory(Vol.1, pp. 187-207) London:Karnac.

Knauss, W. (2005). The group in the unconscious: A bridge between the individual and Society. Revista Portuguesa de Grupanálise,6, 53-62.Recuperado em 20 de Agosto de 2015 de http://www.grupanalise.pt/en/images/ stories/revistaspg2005/Thegroupintheunconscious WKnauss_Revista_SPG2005_53-62.pdf

Lavie,J. (2011).The lost roots of the theory of group analysis: Inter-relational individuals or persons. InE. Hopper,\&H. Weinberg (Eds.),The social unconscious in persons, groups and societies. Mainly Theory(Vol.1, pp.155-175).London: Karnac.

Mojovic, M. (2011). Manifestations of psychic retreats in social systems. In E. Hopper,\& H. Weinberg, H. (Eds.),The social unconscious in persons, groups and societies.Mainly Theory(Vol.1, pp. 209-232). London:Karnac Books.

Nitzgen,D.(2011).The concept of the social unconscious in the work of S.H. Foulkes. InE.Hopper,\&H. Weinberg (Eds.),The social unconscious in persons, groups and societies. Mainly theory (Vol.1, pp.3-21). London:Karnac.

Penna, C. M. P. (2009).Grandes grupos: dinâmica e terapia. Revista da SPAGESP,10(1), 19-25.

Penna, C. (2014). Psicanálise em extensão, psicanálise em contexto: Investigações psicossociais em sociedades traumatizadas. RevistaTrieb, 13(2), 15-32.

Pertegato,E.,\&Pertegato,G.(2013).From psychoanalysis to group analysis: The pioneering work ofTrigant Burrow. London:Karnac.

Scholz, R. (2014). (Foundation-) Matrix Reloadedsome remarks on a useful concept and its pitfalls. Group Analysis, 47(3), 201-212.doi: $10.1177 / 0533316414545838$

Volkan,V.(2002).The Third Reich in the unconscious: Transgenerational transmission and its consequences. New York: Brunner-Routledge.

Volkan, V. (2004).Blind trust: Large groups and his leader in times of crisis and terror. Charlottesville: Pitchstone. 
Volkan,V.(2013).Enemies on the couch: A psychopoliticaljourney through war and peace. Durham: Pitchstone Publishing.

Weinberg, H. (2007).So what's is this social unconscious anyway? GroupAnalysis, 40(3), 307-320.

Winnicott, D.(1971).O brincar e a realidade. Rio de Janeiro: Imago.

\section{Endereço para correspondência:}

Carla Penna

Endereço: Av. Visconde de Albuquerque, no 694/402,

Leblon. Rio de Janeiro/RJ. CEP 22450-000

E-mail: carlapenna@ig.com.br

Endereço para correspondência:

Claudia Amorim Garcia

Endereço: Rua Gal. Glicerio, nº 35/1202, Laranjeiras. Rio de Janeiro/RJ. CEP 22245-120

E-mail: clauag@uol.com.br 